\title{
STUDY OF FORMULATION VARIABLES OF THERMOPLASTIC REFLECTING MATERIALS FOR TRAFFIC MARKING
}

\author{
ESTUDIO DE VARLABLES DE LA FORMULACION DE MATERLALES \\ TERMOPLASTICOS PARA USO VLAL
}

\author{
A.C. Aznar, J.J. Caprari' ${ }^{1}$, J.F. Meda and O. Slutzky
}

\section{SUMMARY}

Nine formulations of thermoplastic materials for traffic marking were prepared using a resin based on maleic anhydride modified with rosin in different proportions $(18,22$ and 26\%). As plasticizer a liquid coconut long oil alkyd resin (100\% solids) was employed.

Hiding pigment was titanium dioxide; calcium carbonate and micronized talc were used as extenders. Coarse marble powder is used to facilitate the incorporation of glass beads. The operation was made employing a double $Z$ mixer oil heated to obtain a mass temperature of 180-190 ${ }^{\circ} \mathrm{C}$. The mixer was provided with two asynchronous arms rotating at $46 \mathrm{rpm}$.

Dry and wet abrasion tests were carried out and the obtained results indicated that wearing values are three times greater in the case of the wet test.

It is demonstrated that plasticization degree controls hardness variation as a function of temperature, determining a critical point which is the beginning of an abrupt reduction of hardness. Water absoption increases when plasticizer content increases. Matrix correlation of tests results was used to analize the obtained numeric values.

Keywords: thermoplastic materials, reflecting properties, agglutinant, dry abrasion test, wet abrasion test, bond strength, water elimination rate.

\section{INTRODUCTION}

Frequently reflecting thermoplastics applied in city streets, roads or highways lost their efficiency due to the wearing or to the partial detachment of the used materials. The appareance and physical characteristics were modified.

The adequate life-time is a funtion of different variables [1], acting individually or as a whole: adhesion to the surface where they were applied on (asphalt or concrete), resistance to abrasion and weathering (moisture due to rain, dew remaining long time in contact with

${ }^{1}$ Miembro de la Carrera del Investigador del CONICET 
thermoplastic marks), high temperatures producing deformation or low temperatures disminishing elasticity and favouring checking or cracking of the coat.

An important aspect is related to the influence of traffic intensity and the rolling action of tires, specially the pressure when the tire takes contact with the line or the suction when rolling over them. A high quality result is related to the components of the formulation and to the adequate cleaning of the surface before application. A best performance was always obtained in asphalt pavements [2].

The objective of this research is to determine the influence of composition variables (pigment/binder ratio, resin content, plasticizer type and content, fillers employed, and PVC) on the adhesion or wearing resistance of the thermoplastic applied on a concrete surface.

\section{EXPERIMENTAL}

Nine samples of thermoplastics reflecting materials were formulated, containing as agglutinant a resin based on maleic anhidride and modified with rosin (A.I.= 14; melting point $114^{\circ} \mathrm{C}$ ). The modified resin was used in 18,22 or $26 \%$ on the total formulation. As plasticizer a coconut oil alkyd resin was employed (without organic solvents) in a proportion between 2.7 and 6.5 per cent.

As hiding pigment titanium dioxide rutile type was employed, to obtain a white colour with high luminosity ( $Y>80$ ). Pigment formulation was completed using fillers as calcium carbonate and talc, which are of good wearing resistence. Samples formulation were indicated in Table 1.

\section{TABLE 1}

Composition of the thermoplastic materials*

\begin{tabular}{|lccccccccc|}
\hline \multicolumn{1}{r|}{ Material } & IA & IB & IC & IIA & IIB & ICC & IIIA & IIIB & IIC \\
\hline Maleic resin & 18.0 & 22.0 & 26.0 & 18.0 & 22.0 & 26.0 & 16.0 & 22.0 & 26.0 \\
Alkyd resin & 2.7 & 3.3 & 3.9 & 3.6 & 4.4 & 5.2 & 4.5 & 5.5 & 6.5 \\
Titanium dioxide & 10.0 & 10.0 & 10.0 & 10.0 & 10.0 & 10.0 & 10.0 & 10.0 & 10.0 \\
Glass beads & 20.0 & 20.0 & 20.0 & 20.0 & 20.0 & 20.0 & 20.0 & 20.0 & 20.0 \\
Marble & 22.4 & 20.3 & 18.2 & 22.0 & 19.8 & 17.6 & 21.6 & 19.3 & 17.0 \\
Calcium carbonate & 22.4 & 20.3 & 18.2 & 22.0 & 19.8 & 17.6 & 21.6 & 19.3 & 17.0 \\
Talc & 4.5 & 4.1 & 3.6 & 4.4 & 4.0 & 3.6 & 4.3 & 3.9 & 3.5 \\
\hline
\end{tabular}

A double $\mathrm{Z}$ mixer (Fig. 1) was used for the thermoplastic preparation, having the mixer two asyncrhonic arms, one of them rotating at $46 \mathrm{rpm}$. For heating a mineral thermic fluid which circulates in the heating jacket was employed (maximum temperature $300^{\circ} \mathrm{C}$ ).

Titanium dioxide, fillers and glass beads were incorporated at $180-190{ }^{\circ} \mathrm{C}$. The operation at this temperature lasts 30 minutes. After that, the product obtained was casted in special molds. 


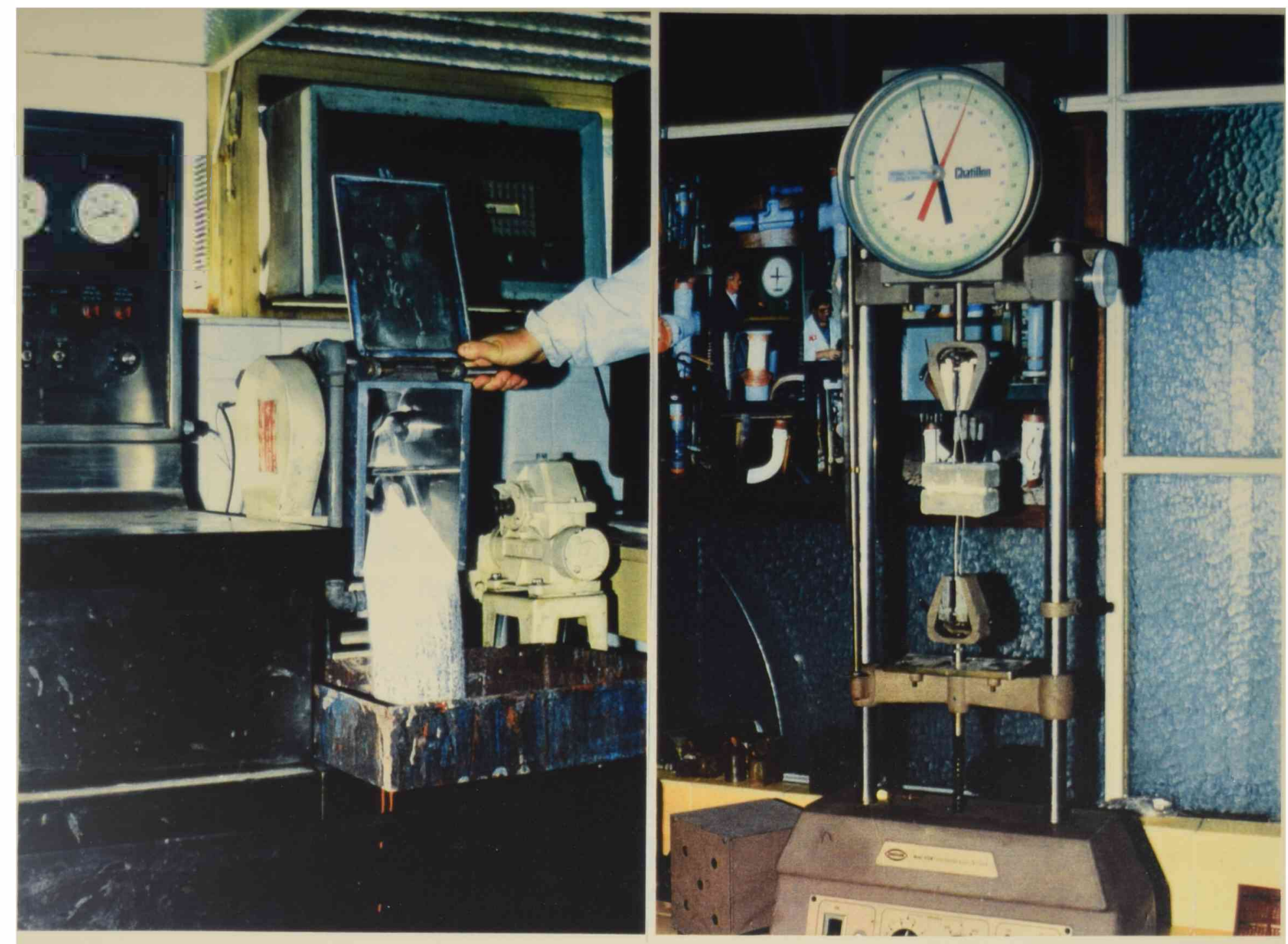

Fig. 1.- Double $\mathbf{Z}$ mixer for test samples preparation.

Fig. 2.- Adhesion-strength determination by CIDEPINT method.

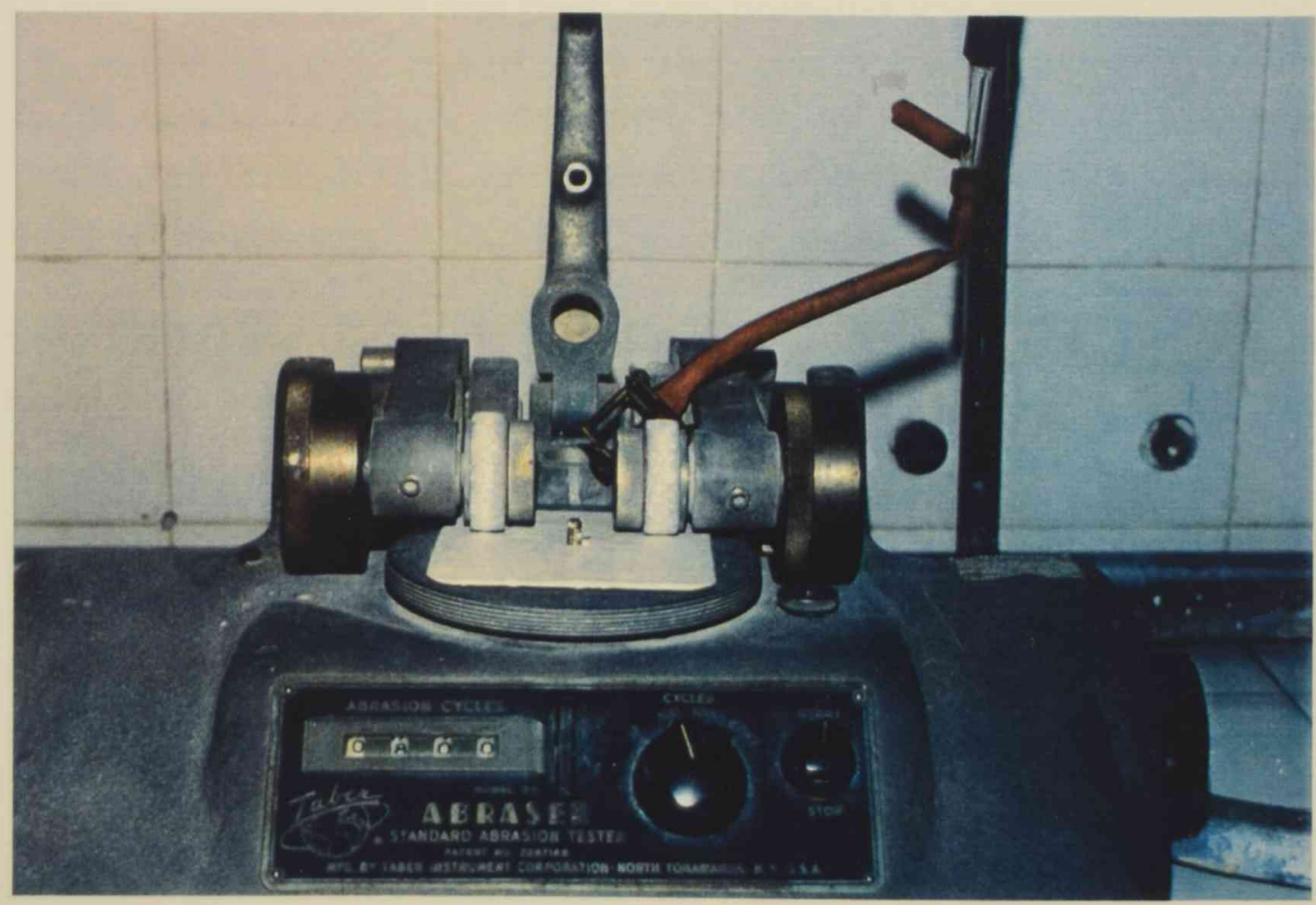

Fig. 3.- Wet and dry abrasion test equipment. 

The samples tests were performed at different temperatures; wet and dry abrasion, Shore A hardness, adhesion-cohesion, water absorption and water elimination rate were determined.

For the wet and dry abrasion test [3],circular specimens were employed (80 mm diameter and $3 \mathrm{~mm}$ thick). After 24 hours samples were abraded using a Taber Abraser equipment, with a H-22 abrasive and $1000 \mathrm{~g}$ load (ASTM D 4060). The dust produced by the wearing operation was eliminated constantly by flowing pressurized air. When a track is formed as a consequence of wearing, the sample is weighed with an exactitude of $1 \mathrm{mg}$. After that, the wearing operation is continued along 100 revolutions of the equipment and newly weighed. The difference between the two values obtained is expressed as dry wearing (Fig. 2).

After finishing the previous test, distilled water is added to the track and the operation continued during 100 revolutions more. The sample is now conditioned for water elimination and weighed. The difference with the previous value is expressed as wet wearing.

Shore A hardness [4] at temperatures between 40 and $70{ }^{\circ} \mathrm{C}$ was determined each $5^{\circ} \mathrm{C}$, according to DIN 53505 . In this case test plates are $50 \mathrm{~mm}$ diameter and $3 \mathrm{~mm}$ thick; the value was registered after 15 seconds. Samples were stabilized during 1 hour at test temperature before hardness determination.

To obtain adhesion and cohesion strength values a method developed at CIDEPINT was employed [5,6]. The melted material was put in the midst of concrete probes ( $3 \mathrm{~mm} \mathrm{trick}$ ), previously primed with an acrylic varnish and preheated at $40{ }^{\circ} \mathrm{C}$. An iron flexible wire was inserted in test probes to allow the clamps of a dinamometer. The traction effort was performed at a velocity of $200 \mathrm{~mm} \cdot \mathrm{min}^{-1}$ and at a temperature of $20^{\circ} \mathrm{C}$ (Fig. 3).

For the determination of water absorption and water elimination rates $[7,8,9]$, specimens of $50 \mathrm{~mm}$ diameter and $3 \mathrm{~mm}$ thick were prepared and weighed with the precision of $1 \mathrm{mg}$. Hung by means of a copper wire, they were completely submerged in distilled water at $20 \pm 1^{\circ} \mathrm{C}$ for 24 hours. After that, they were dried with filter paper and weighed; the operation was made after 48 and $72 \mathrm{~h}$. Absoption values were obtained by difference with the initial weight of the samples .

Afterwards the probes were conditioned at $20^{\circ} \mathrm{C}$ and $50 \% \mathrm{HR}$. By weighing, water elimination values were obtained.

\section{DISCUSSION}

The maleic resin is the agglutinant used in the formulation of thermoplastic traffic materials. The modification of physical properties (reduction of melting point and adequate elasticity characteristics) by means of an alkyd resin improved the system wetting, facilitating the incorporation of the hiding pigment $\left(\mathrm{TiO}_{2}\right)$, fillers and glass beads. In those conditions a homogeneous distribution of glass beads was obtained. This is a very important aspect in field behaviour; in wearing, an adequate distribution of beads in the mass assures adequate night visibility, during a long period.

A certain correlation was observed between the thermoplastic traffic materials composition and the values of the obtained physical properties (Table 2). 
TABLE 2

Correlation between materials composition variables and physical properties

\begin{tabular}{|c|c|c|c|c|c|c|c|c|c|c|c|}
\hline $\mathbf{n}$ & $\mathbf{R}$ & $\mathbf{P}$ & $\mathbf{M}$ & $\mathbf{C}$ & $\mathbf{T}$ & $\mathbf{W}^{+}$ & $\mathbf{A S}$ & $\mathbf{D}$ & $\boldsymbol{\Delta}$ & $\mathbf{P V C}$ & $\mathbf{W}^{-}$ \\
\hline $\mathbf{R}$ & 1.00 & 0.58 & -0.97 & -0.93 & -0.98 & -0.92 & 0.98 & -0.31 & -0.89 & -0.97 & -0.90 \\
\hline $\mathbf{P}$ & 0.58 & 1.00 & -0.75 & -0.77 & -0.72 & -0.71 & 0.43 & -0.94 & -0.73 & -0.76 & -0.75 \\
\hline $\mathbf{M}$ & -0.97 & -0.75 & 1.00 & 0.97 & 0.99 & 0.95 & -0.91 & 0.51 & 0.93 & 1.00 & 0.94 \\
\hline $\mathbf{C}$ & -0.93 & -0.77 & 0.97 & 1.00 & 0.97 & 0.98 & -0.85 & 0.55 & 0.93 & 0.97 & 0.98 \\
\hline $\mathbf{T}$ & -0.98 & -0.72 & 0.99 & 0.97 & 1.00 & 0.95 & -0.91 & 0.48 & 0.91 & 1.00 & 0.94 \\
\hline $\mathbf{W}^{+}$ & -0.92 & -0.71 & 0.95 & 0.98 & 0.95 & 1.00 & -0.87 & 0.50 & 0.84 & 0.95 & 1.00 \\
\hline $\mathbf{A S}$ & 0.98 & 0.43 & -0.91 & -0.85 & -0.91 & -0.87 & 1.00 & -0.15 & -0.83 & -0.91 & -0.84 \\
\hline $\mathbf{D}$ & -0.31 & -0.94 & 0.51 & 0.55 & 0.48 & 0.50 & -0.15 & 1.00 & 0.46 & 0.52 & 0.55 \\
\hline $\boldsymbol{\Delta}$ & -0.89 & -0.73 & 0.93 & 0.93 & 0.91 & 0.84 & -0.83 & 0.46 & 1.00 & 0.92 & 0.84 \\
\hline $\mathbf{P V C}$ & -0.97 & -0.76 & 1.00 & 0.97 & 1.00 & 0.95 & -0.91 & 0.52 & 0.92 & 1.00 & 0.95 \\
\hline $\mathbf{W}^{-}$ & -0.90 & -0.75 & 0.94 & 0.98 & 0.94 & 1.00 & -0.84 & 0.55 & 0.84 & 0.95 & 1.00 \\
\hline
\end{tabular}

\begin{tabular}{clrl}
\multicolumn{5}{c}{ Key of the table } \\
R: & resin & P: & Plasticizer \\
M: & marble powder & C: & calcium carbonate \\
T: & micronized talc & W $:$ & water absorption \\
AS: & adhesion-strength & D: & hardness at $55^{\circ} \mathrm{C}$ \\
$\Delta:$ & abrasion & PVC: & PVC \\
& & W: $:$ & water elimination
\end{tabular}

In the dry abrasion test the trend of wearing is determined by pigment volume concentration of the different samples. Two series of wearing values were obtained (Fig. 4).

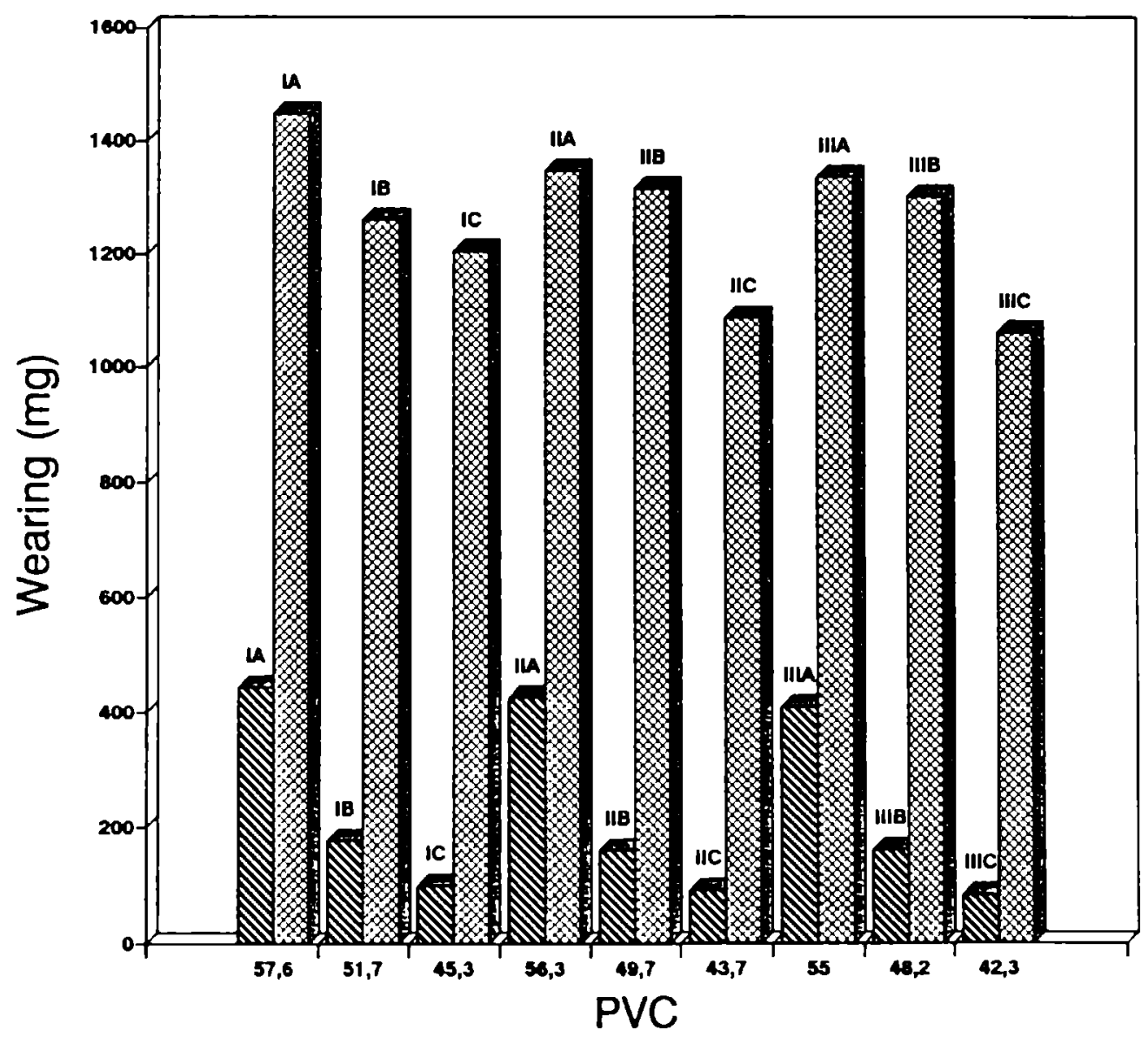

Dry abrasion Wet abrasion

Fig. 4.- Comparutive result of dry and wet abrasion test. 
The wet abrasion test shows greater wearing values than those obtained in the dry abrasion test.

Results of hardness test, as a funtion of temperature, are related to the plasticization degree of the agglutinant resin. This is particularly observed over a temperature of $55^{\circ} \mathrm{C}$, which is considered critical; over this temperature value, hardness disminishes abruptly in practically all the samples. This characteristics is independent of plasticizer level and PVC values (Fig. 5).
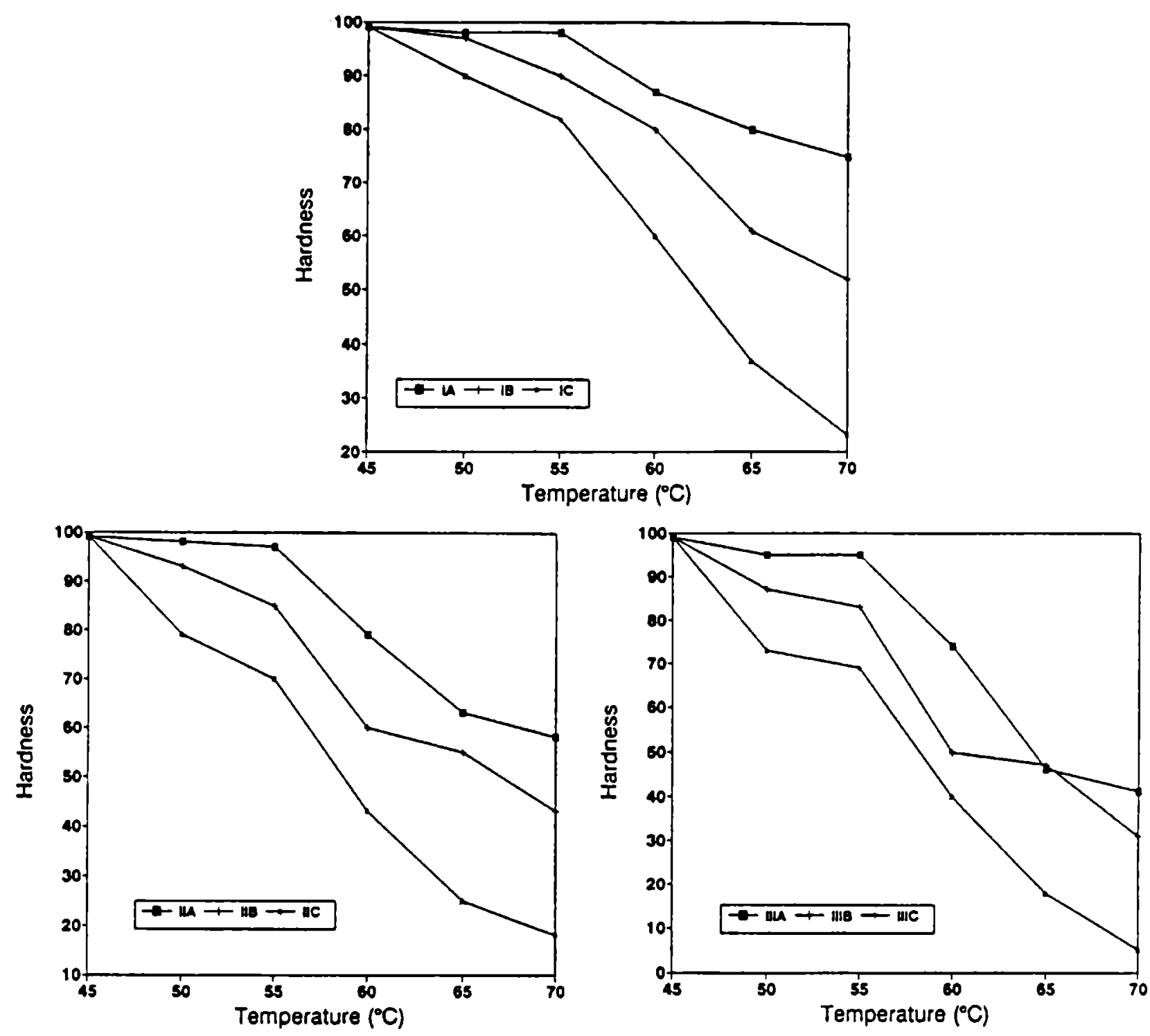

Fig. 5.- Varlations of hardness as a function of the temperature.

The indicated critical temperature is a harmful interactive factor in the material application.

Adhesion-tension values are lineally dependent on the employed resin (Fig. 6) and not related with the plasticizer level; the obtained values expressed in $\mathrm{kg}_{\mathrm{cm}} \mathrm{cm}^{-2}$ are of the same order than those of the standards used to qualify this type of materials.

In the results of water absorption (Fig. 7) and water elimination (Fig. 8) tests, the increase of weight of the termoplastic mass during inmersion is faster than the elimination value. 


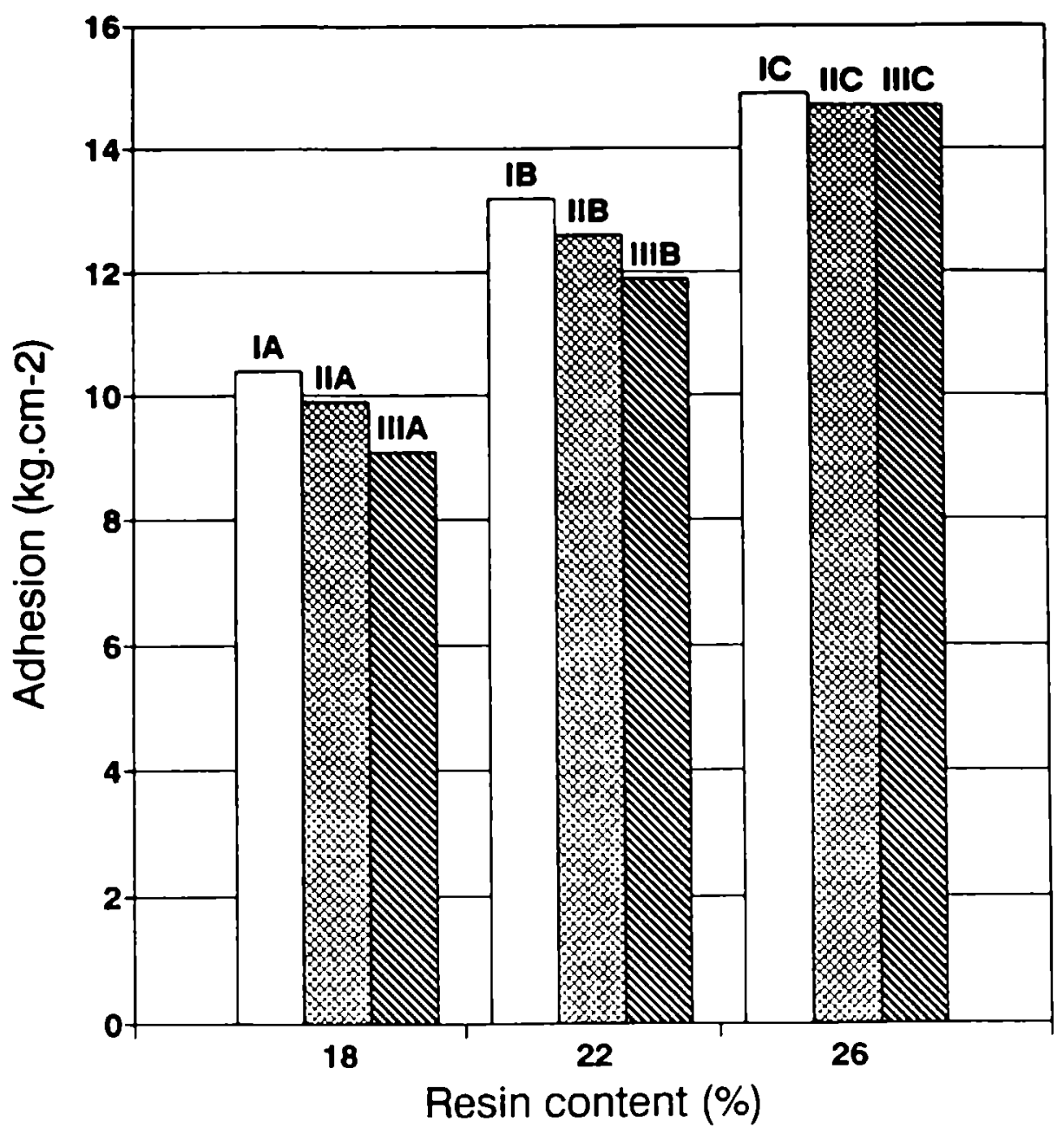

Flg. 6.- Variations in adhesion-strength as a function of resin content.

\section{CONCLUSIONS}

1.- The wet abrasion wearing values are higher than those obtained in the dry abrasion test. Wearing is directly dependent on the plasticizer level but independent of the maleic resin content.

2.- Plasticization degree has a high influence on hardness variation as a function of temperature. A critical point appears at $55{ }^{\circ} \mathrm{C}$ with a sudden reduction of hardness values.

3.- Adhesion strength is dependent on the resin content, a higher content increases adhesion strength. This parameter is independent of the plasticization degree.

4.- Water absorption decreases when plasticizer increases, independently of the resin content. Water elimination rate decreases too.

5.- The retained moisture of the thermoplastic traffic material after inmersion must be considered as a harmful property in relation to the wearing resistence in service. 

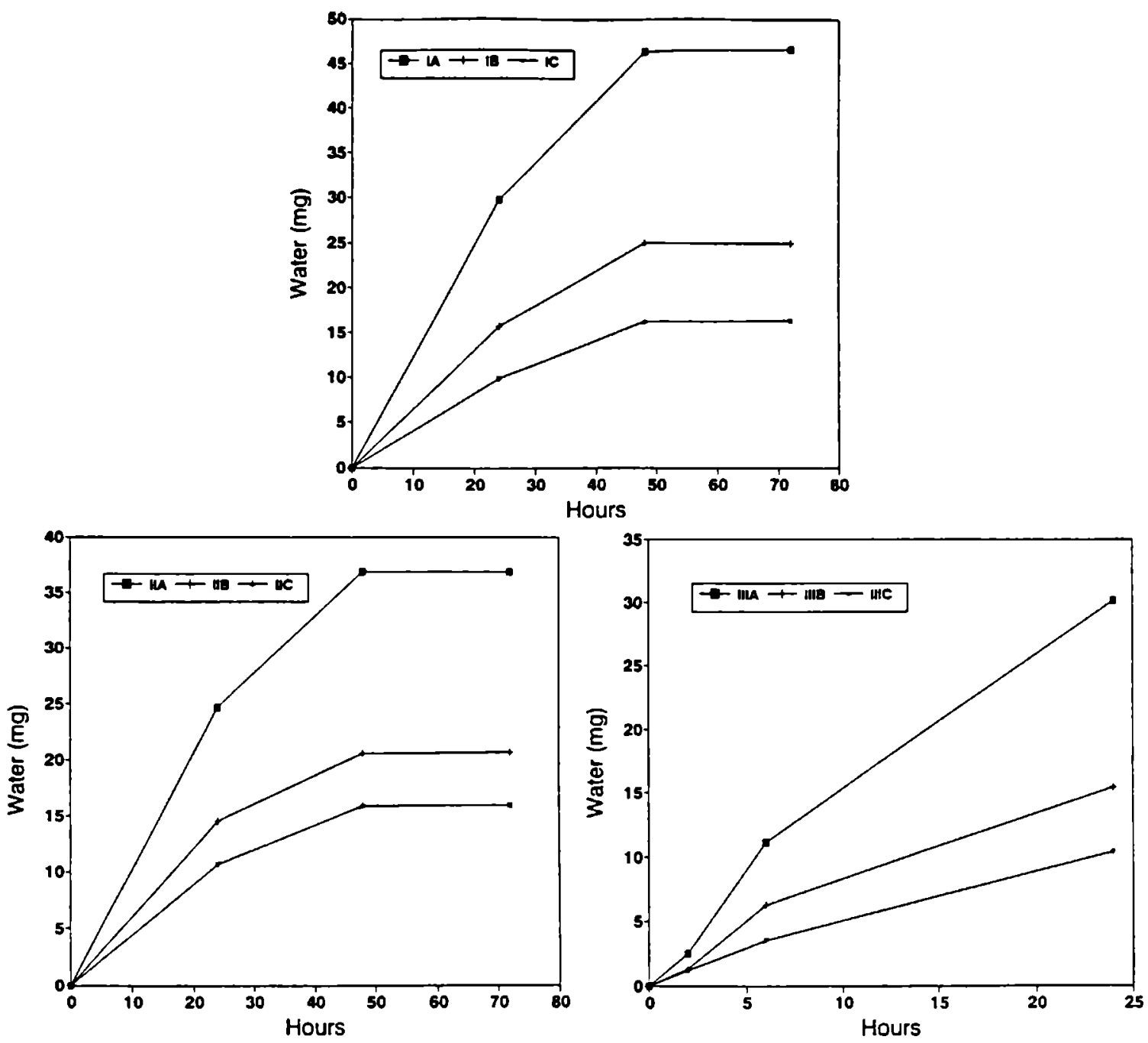

Fig. 7.- Water absorption values as a function of time.
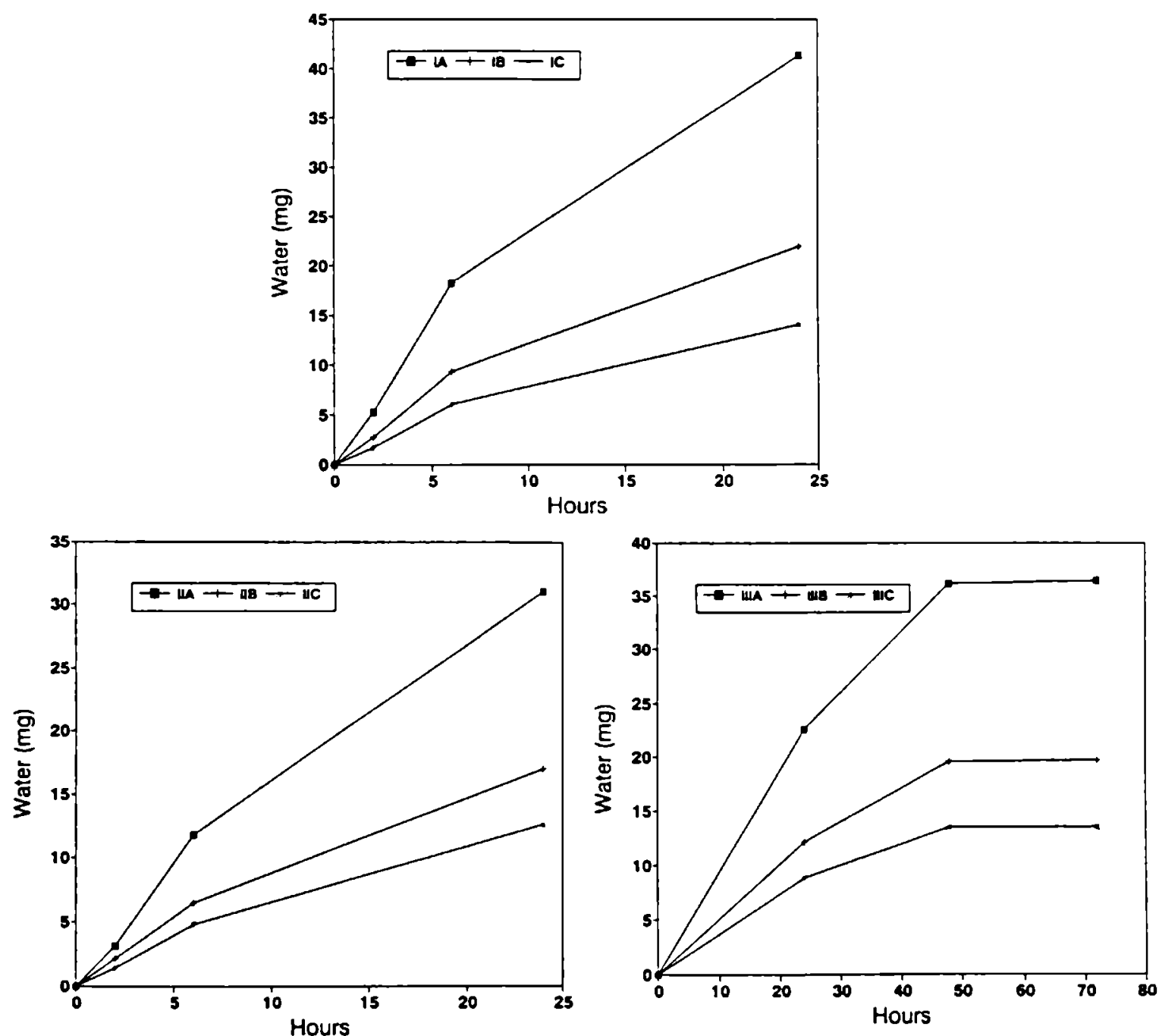

Fig. 8.- Water elimination values as a function of time. 


\section{REFERENCES}

[1] Lindberg, B., "Painting Concrete“, J. Oil. Col. Chem. Assoc., 57, 100-113 (1974).

[2] Nutt, N.O., "A Quantitative Method for Determining the Adhesion of Coatings to Plastics“, J. Oil Col. Chem. Assoc., 75, 53-58 (1992).

[3] Departamento de Entradas Rodagen de Estado de Sao Pablo. Especificacoes e metodos de ensaios de materiais de sinalizacao redoviaria, 1990.

[4] ASTM D-2240. Rubber property - Durometer Hardness, test 35, $702-705$ (1980).

[5] ASTM D-4796. Standard test method for bond strength of thermoplastic traffic marking materials, Vol. 06.01, 846-849 (1980).

[6] Aznar, A.C., "Proposal for a method to determine the cohesive and adhesive bond strength of traffic marking thermoplastic materials", CIDEPINT-Anales, 215-226 (1994).

[7] Norma IRAM 1211. Recubrimientos termoplásticos para la demarcación de pavimentos (1981).

[8] Norma IRAM 1212. Recubrimientos termoplásticos reflectantes para la demarcación de pavimentos (1981).

[9] Koleske, J.V. (De.), "Paint and Coating Testing Manual", Chapter 66, Fourteenth Edition of the Gardner-Sward Handbook, ASTM Manual Series MNL17 (1995). 